\title{
الفكر التربوي في نهج البلاغة
}

م.م عمار عبد الرزاق جابر

تربية واسط / تربية الحي

الملخص:

دراسة الفكر التربوي الحديث تتويجاً للماضي في ظل مستجدات العصر الأي نعيشه من تطور في

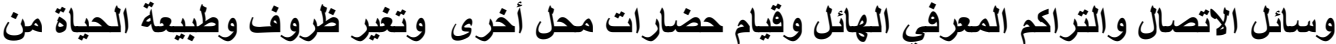

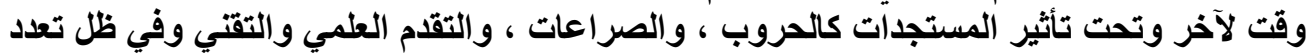

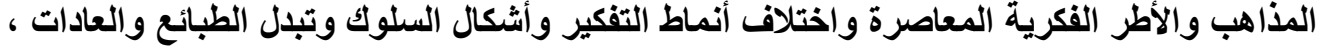

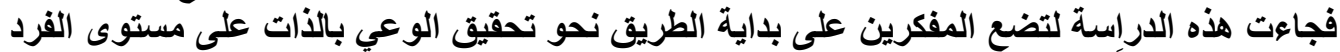

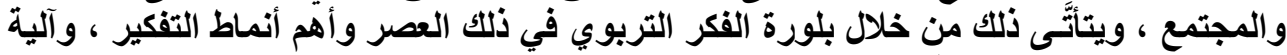

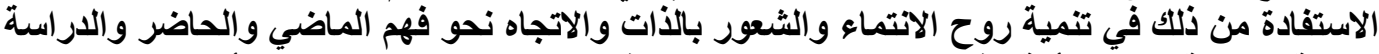

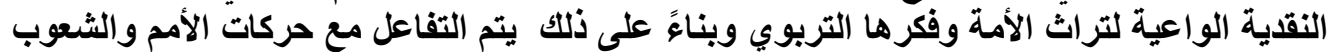

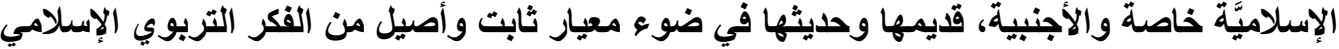

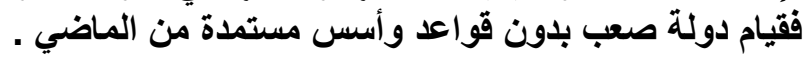

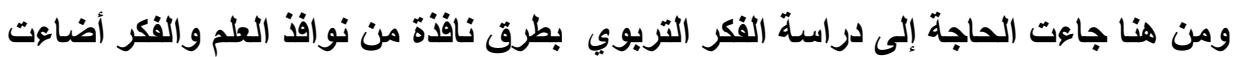

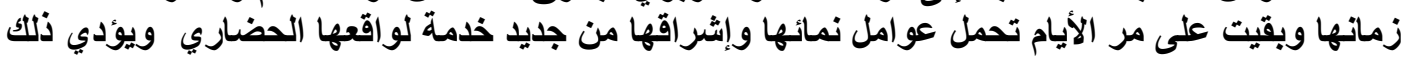

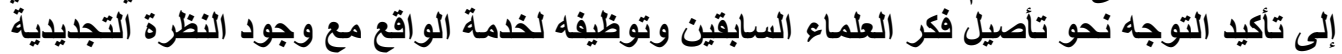

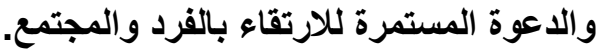

الهدف من الدراسة هو تعرف الفكر التربوي من خلال بعض خطبه الامام علي(عليه السلام)

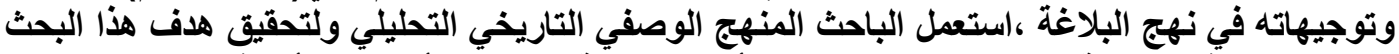

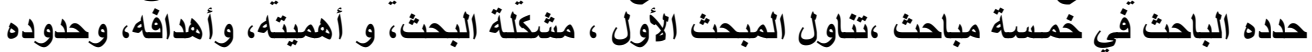

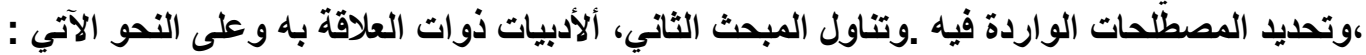

أولاً:- المدخل النظري وتناول:(اسمه، ونسبه ،وحياته) . ثانياً: الاراسات السابقة ذات الصلة بموضوع البحث الحالي. ثالثاً: موازنة الدراسات السابقة . رابعاً: الإفادة من الدراسات السابقة . 
الحمد الله الذي زوّد الإنسان العقل ليعمل بما يطلم ،وبيّن له بالوحي معالم طريقة والصلاة والئل والسلام

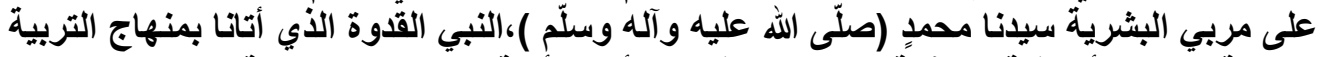

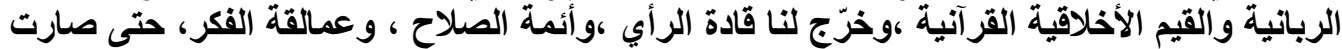

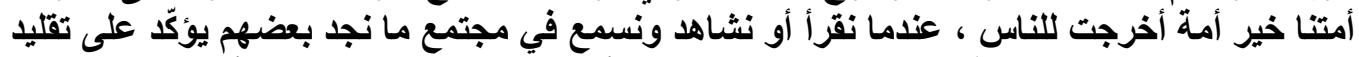

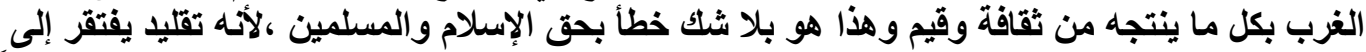

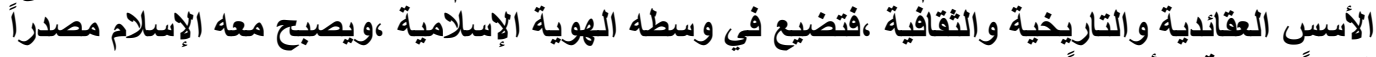
ثانوياً للتربية لا أسناسياً.

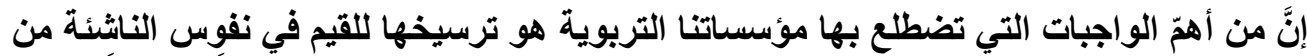

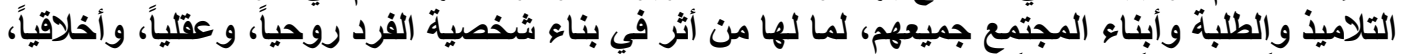

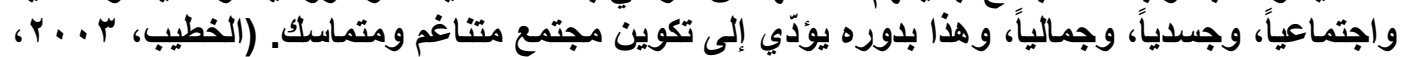

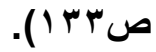

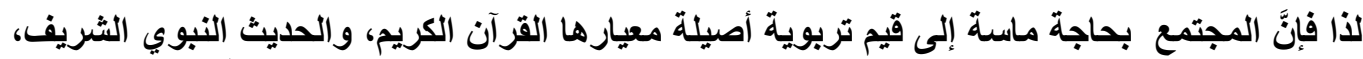

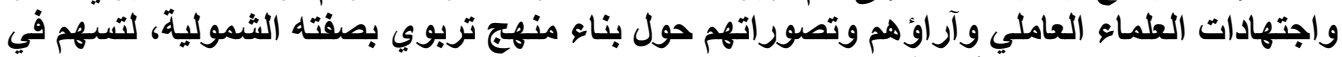

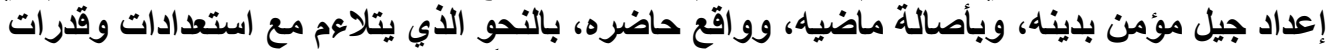

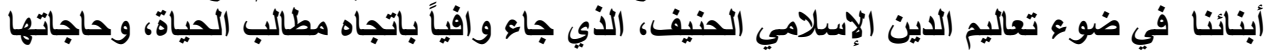

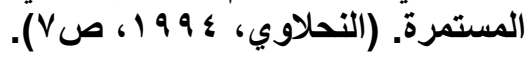

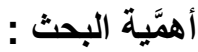

ويّمثل الفكر التربوي الإطار النظري والفكري لما يحتاجه الإنسان في بناء أنظمته التربوية وأبجديات

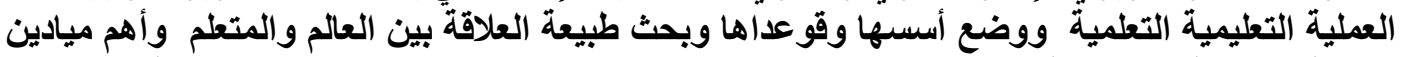

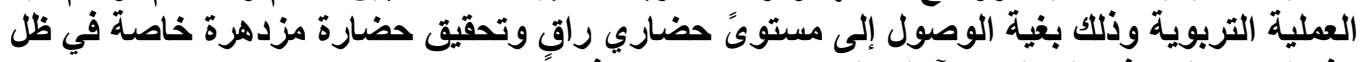

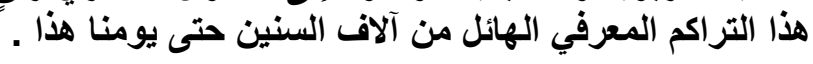

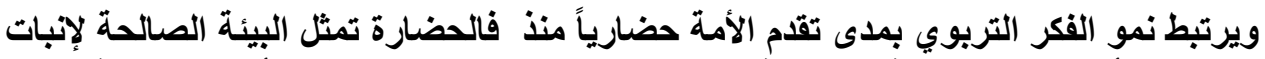

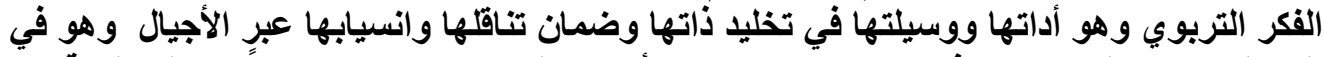

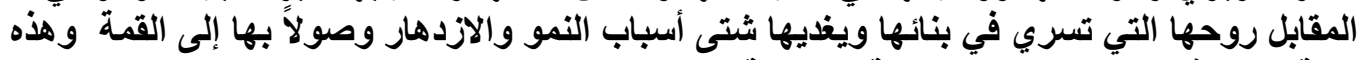

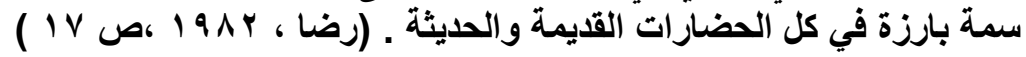


ويسير النمو الحضاري والفكري جنباً إلى جنب وبقدر العمق الحضاري يتعمق النقار النمو الفكري

مجلــــة كليـــــة التربيــــة

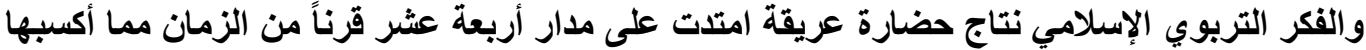

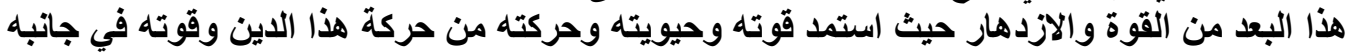

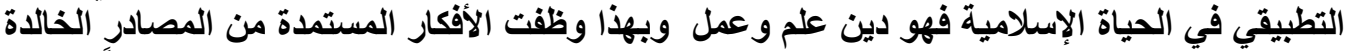

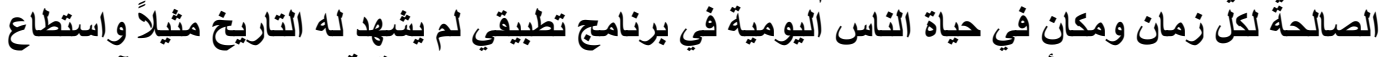

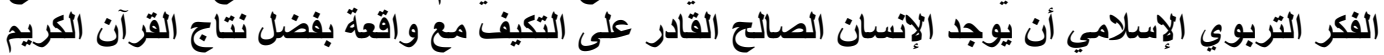

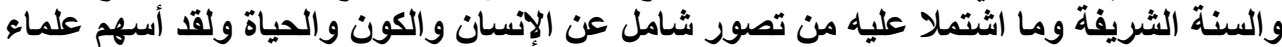

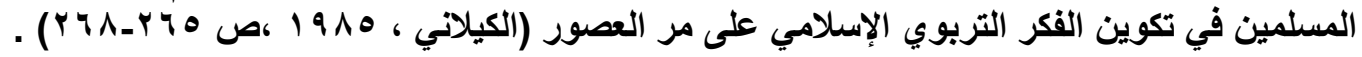

تلخيص أهمية البحث في النقاط الآتية :-

1 ـ شخصية الإمام علي (عليه السلام) فهو يحتاج إلى الكثير من البحث والار اسة. بـ الاهتمام بالدراسات والبحوث الخاصة بتراثنا الزاخر ودراسة فكر العلماء الأين لم ينالوا ما يستحقون من البحث والاراسة والاستفادة من موالهبهم الفذة في التربية والتعليم . r- تسليط الضوء على مفهوم التربية في الفكر الإسلامي. ع - مواجهة التحديات التربوية التي أخذت تتظفل في المجتمع الإسلامي . هـ الأخذ من الفكر التربوي للإمام علي (عليه السلام) في تنشئة أبنائنا وتربيتهم . צ- حاجة الأمة الإسلامية إلى من يذكرها بتراثها وفكر مبدعيها و عظمائها. V- إثراء المكتبات العربية بالبحوث والدراسات الخاصة بالفكر الإسلامي وذلك لحاجة الأمة الماسة لها .

هدف البحث: يهدف البحث الحالي إلى تعرف الفكر التربوي في نهج البلاغة.

$$
1 \text { - إظهار الجانب التربوي في فكر الإمام علي (عليه السلام). }
$$$$
\text { r - الاستفادة من الجوانب التربوية في فكر الإمام علي (عليه السلام). }
$$

ب - و الممارسات التربوية للإمـام علي (عليه السلام)، والاهتمام بما قدّم المسلمون الأوائل من نتاج فكري ولاسيّما آل بيت النبوة الآطهار . 
العـــــــد الرابع والعشرون

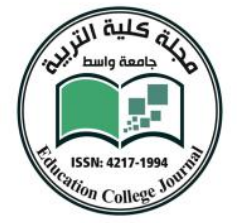

ا ـكتاب نهج البلاغة : من خلال اعتماد مجموعة من الخطب وبيان الجوانب التربويـة فيها ـ وتمّ اختيار بعض الخطب التي لها صلة مباشرة بالتربية ومقسّمة بحسب الأجزاء كما في شرح مع علي محمدعلي دخيل.

\begin{tabular}{|c|c|c|c|}
\hline رقم الصفحة & الخطبة & الجزء & ت \\
\hline$\leqslant 7-\leqslant 0$ & $r M-Y I$ & ج1 & 1 \\
\hline VI $-V$. & $\{r-\varepsilon \mid$ & r & $r$ \\
\hline$\Lambda \gamma_{-} \Lambda 0$ & Tr-Tr & جr & $\mu$ \\
\hline
\end{tabular}

اختلفت المنهجية في البحث الحالي عن البحوث التربوية المتعارف عليها كون البحث يختلف في

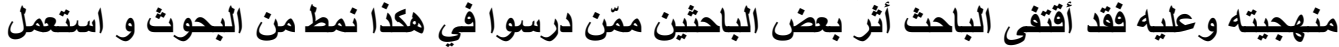

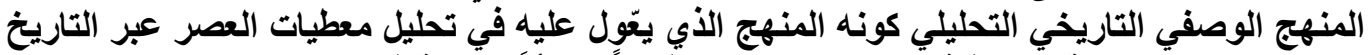
والاتجاهات الاجتماعية والثقافية للمجتمع الإسلامي فضاريلاً عن أنَّ دراسة فيه فكر الإمام علي (عليه السلام) وآرائه التربوية تحتاج إلى تحليل.

: تحديا المصطلحات :

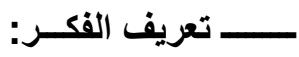

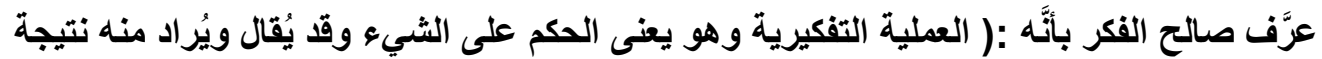

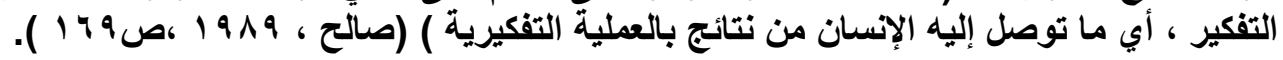

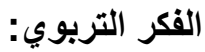

عرَّف مصطفى الفكر التربوي بأنّه :( عبارة عن جزء من فكر إنساني مباع يتسم بالديناميكية والتطور

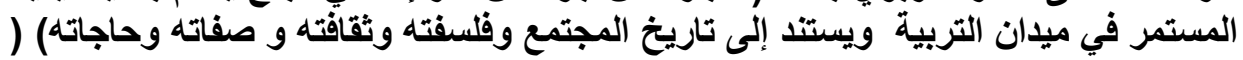

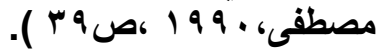
المبحث الثاني/(الخلفية النظرية ) :

مقدمة: يصعب على الباحث الإحاطة والشمولية بشخصية كبيرة كشخصية الإمام علي (عليه السلام)،

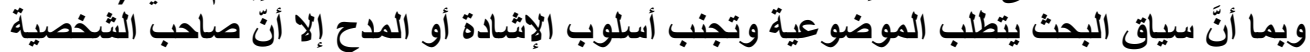

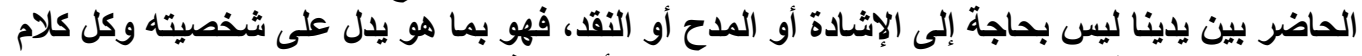

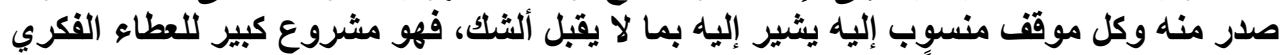
والعقائدي، وعلى الرغم ممًّا وصل ملَ إليه من بناء رصئ رصين في العلم والأخلاق. 
نشأ علي (عليه السلام) جوار الرسول محمد(ص) ولم يفارقه حتى اختاره الله إلى جواره فكان تلميذاً

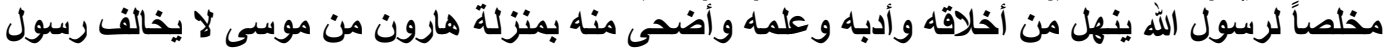

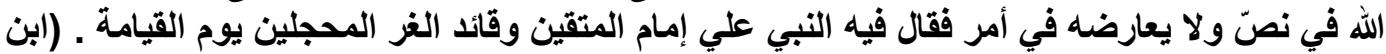

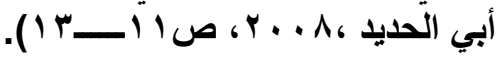

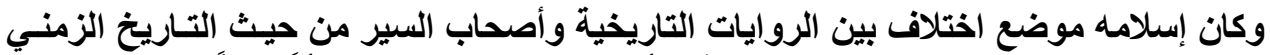

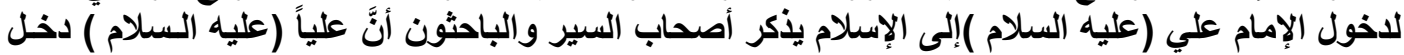

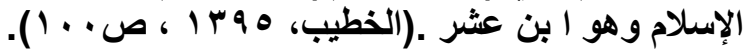

والمرجح وما عليه أكثر الرواة أنَّه :دخل الإسلام وهو ابن ثماني سنوات ، وذلتك لإجمـاع أكثر

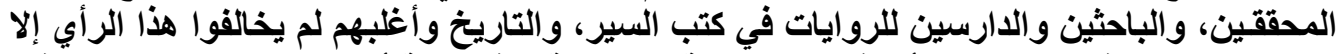

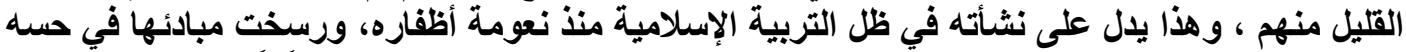

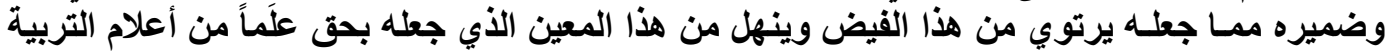

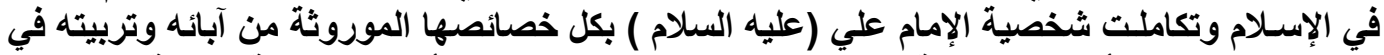

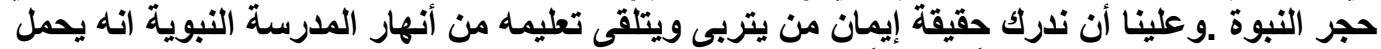

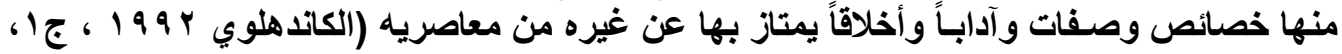

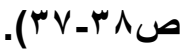

ولابدّ من الإشـارة إلى كتابات بعض المفكرين من غير المسلمين حول الإسلام وحول سيد تلثك الرسالة

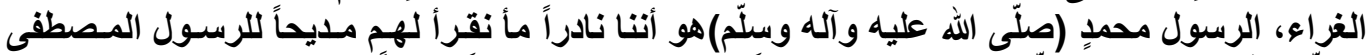

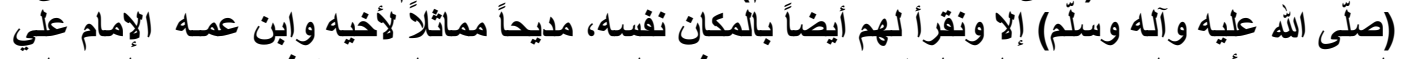

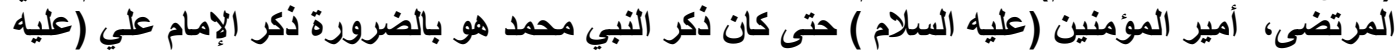

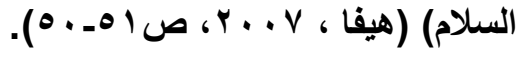

: ثانياً :دراسات سـابقة

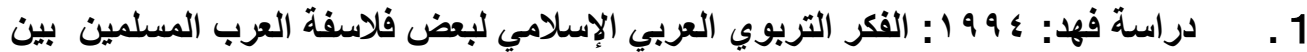

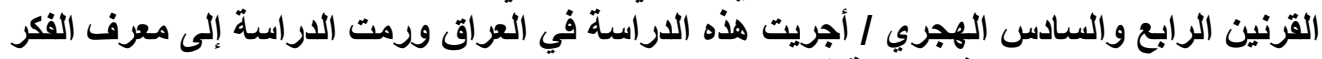

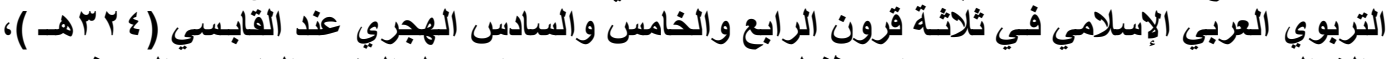

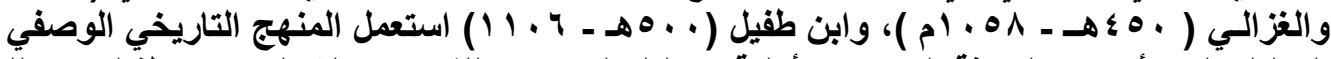

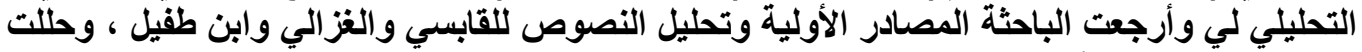

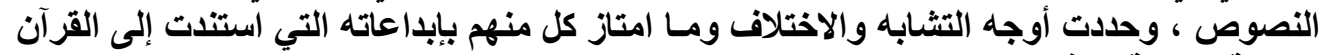

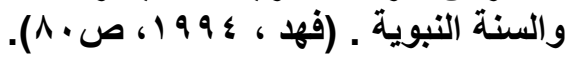

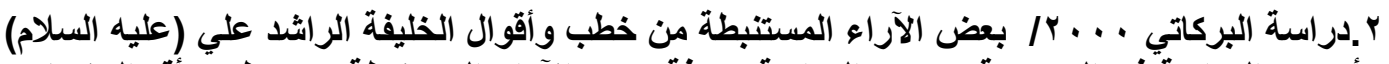

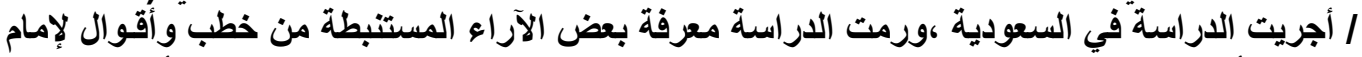

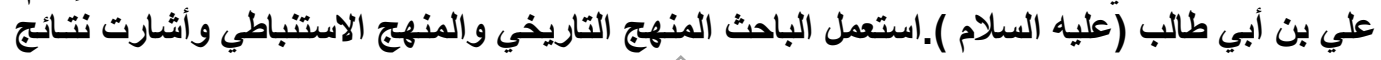




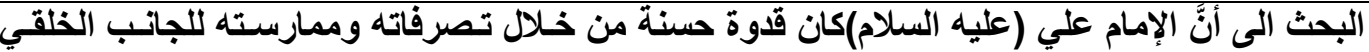

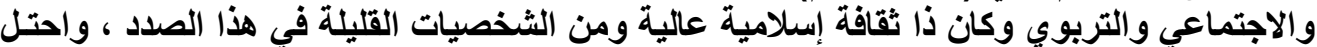

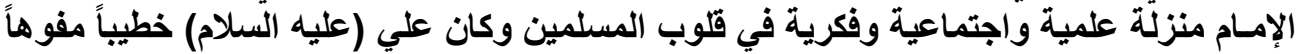

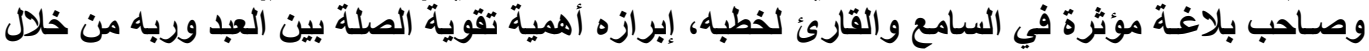

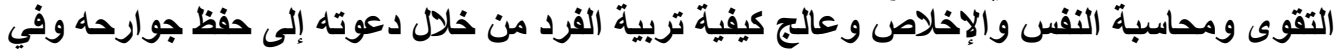

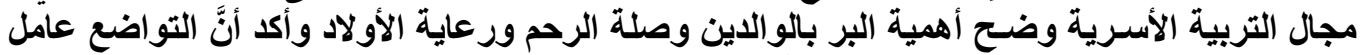

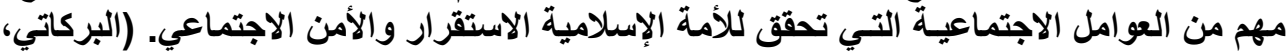

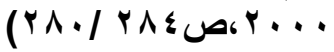

ثالثاً: وقفة مع دراستين السابقة :أجريت دراسة واحدة في العراق كما هي الحال في الدراسة الحالية

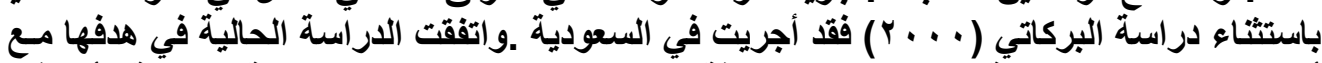

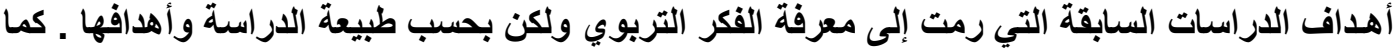

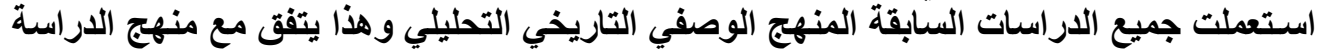

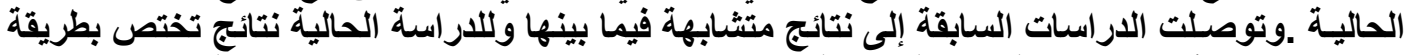

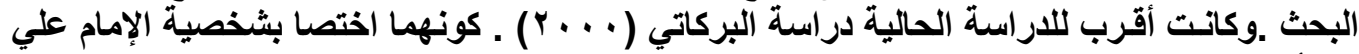
بن أ بـي طالب (عليه السلام). المبحث الثالث/الفكر التربوي في نهج البلاغة .

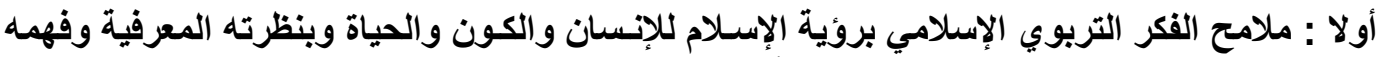

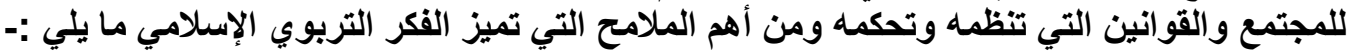

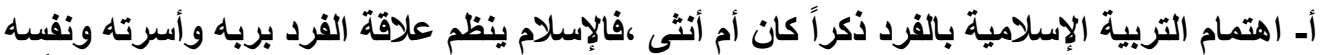

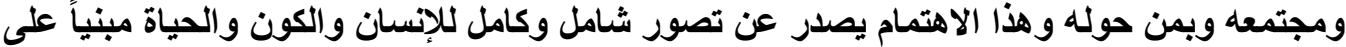

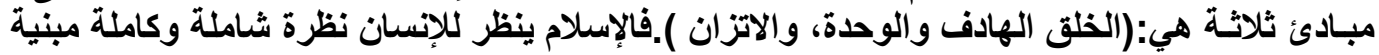

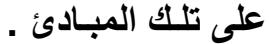

بـ اهتمام التربية الإسلامية بالجانب العملي التطبيقي إذ حذر القرآن الكريم الذين يقولون ولا يفعلون.

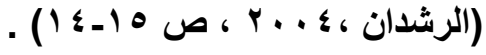

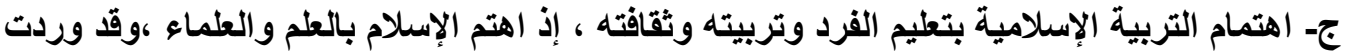

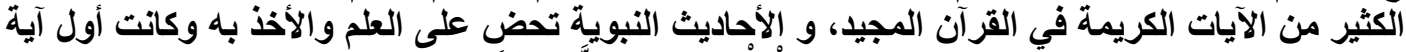

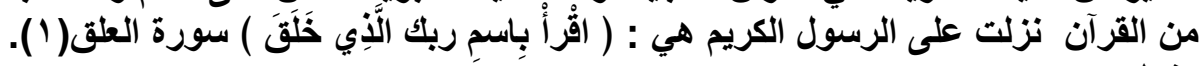

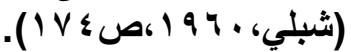

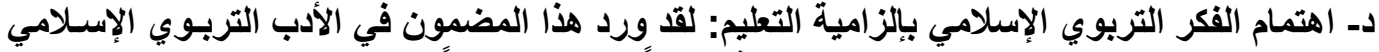
تحت عنوان (( وجوب تعليم الصبيان)) واعتبر ذلإئل حقاً للطفل انسجاماً مع تعاليم الإسلام . ثانياً : مصادر الفكر التربوي الإسلامي : 


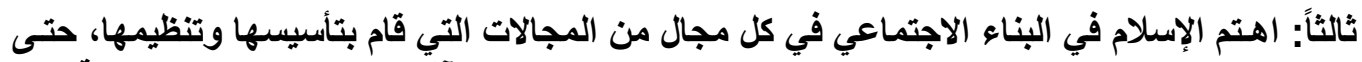

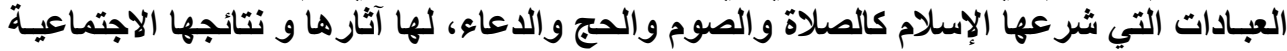

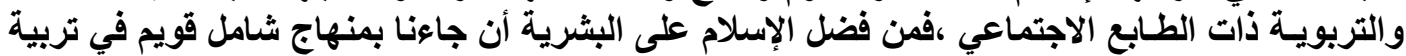

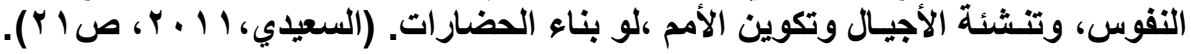

رابعاً :مفهوم التربية في فكر الإمام علي (عليه السلام ):نريد الحديث هنا عن مفهوم التربية من وجهة

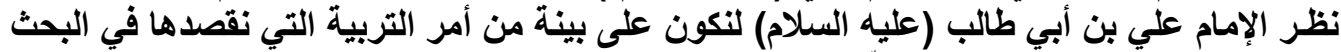

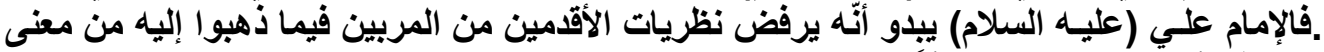

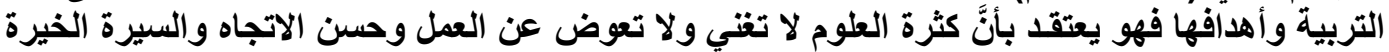

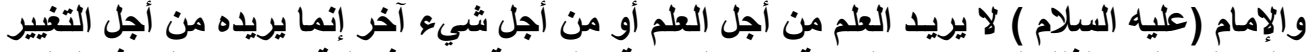

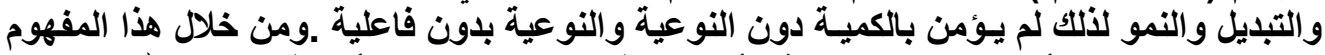

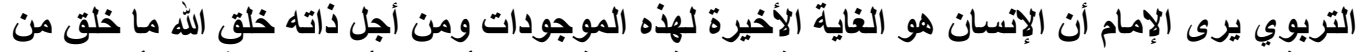

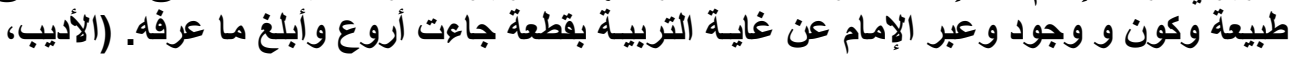

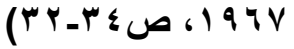

وبهذا يكون الإمام علي (عليه السلام ) قد وضع مفهومه عن ماهية التربية وأهدافها وطبيعتها فهو

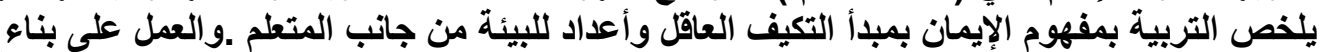

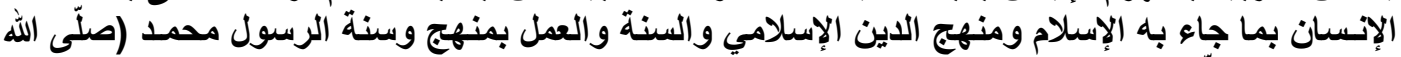

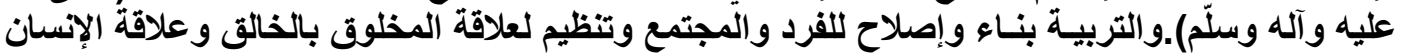
بنفسه ومجتمعه. 


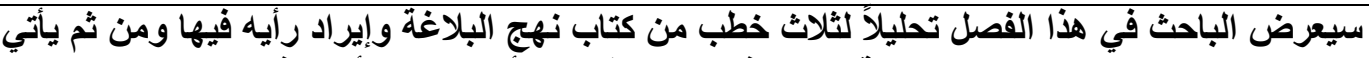

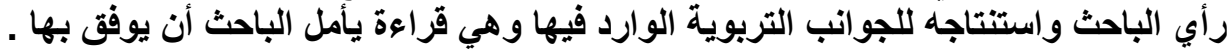

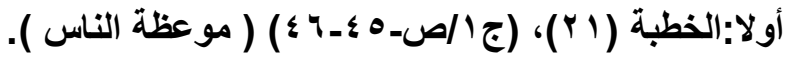

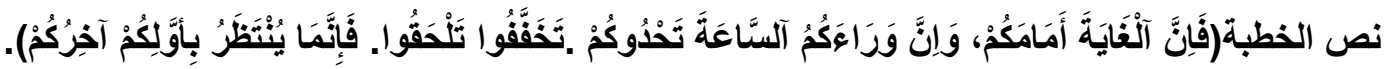

نستتتج من الخطبة بعد استقراعها الجواتب التربوية الآتية :

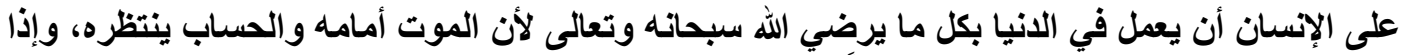

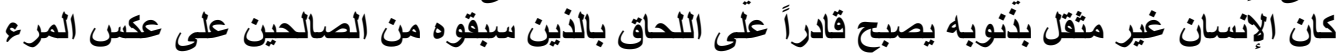

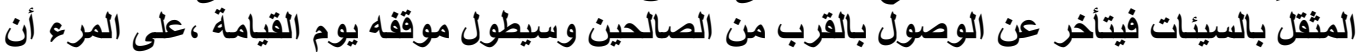

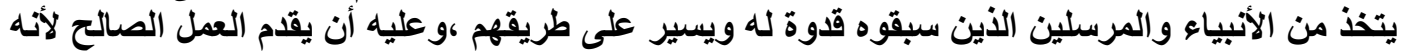

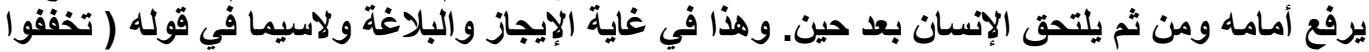

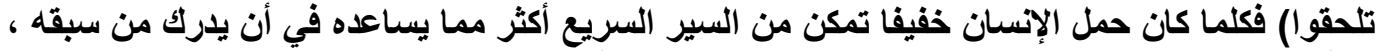

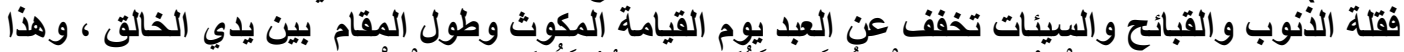

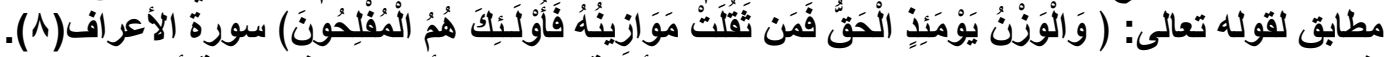

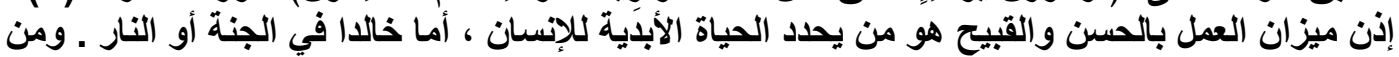

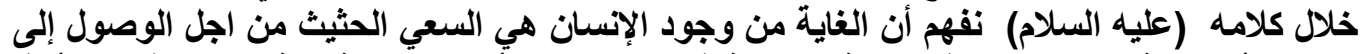

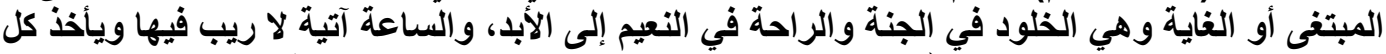

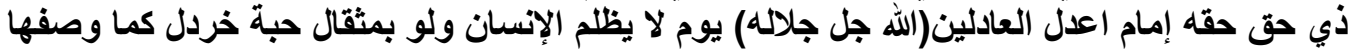
القرآن.

$$
\text { ثانياً: الخطبة ( }
$$

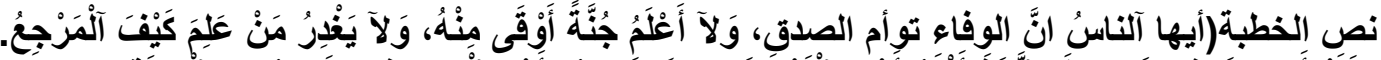

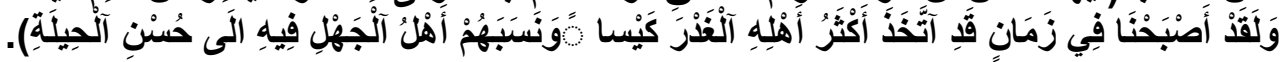

نستتتج من الخطبة السابقة الجوانب التربوية الآتية :

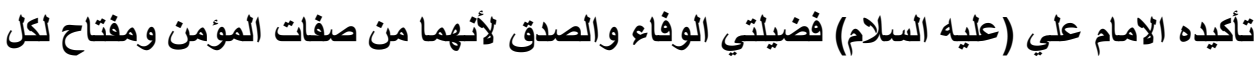

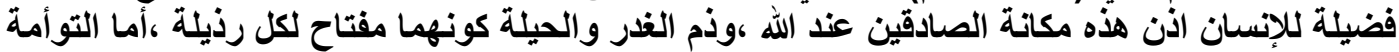

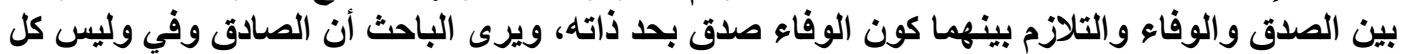

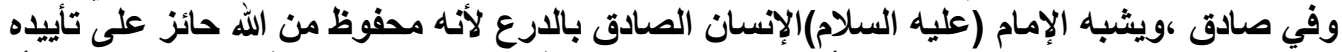

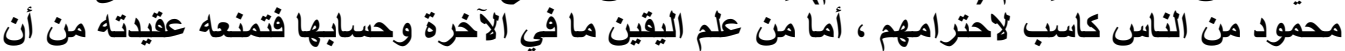

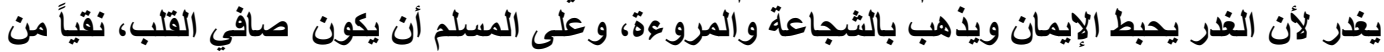

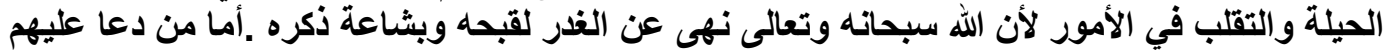

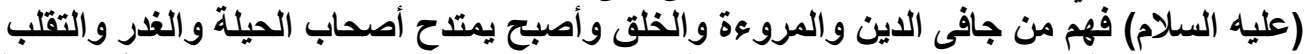
ويصفهم برجاحة العقل وحسن التدبير والكياسة فقد خلطوا والثن الحق بالباطل والصواب الصاب بالخطأ والحقيقة 


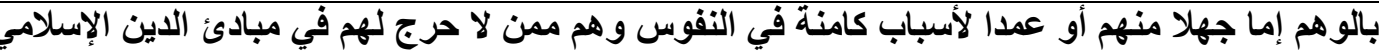

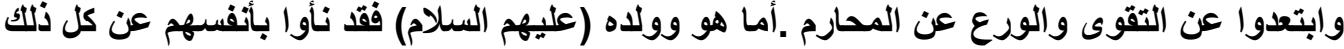

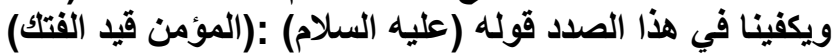

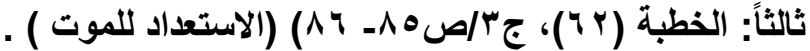

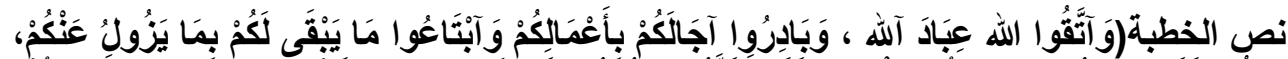

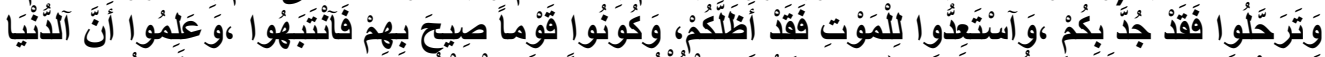

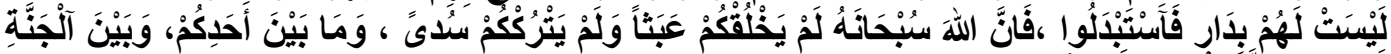

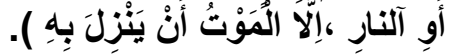

نستنتج من الخطبة السابقة الجوانب التربوية الآتية :

على العامل أن يجعل عمله في الانيا متاعاً الى دار الآخرة ويكون زاده هنائ عمله في الدنيا .وأن

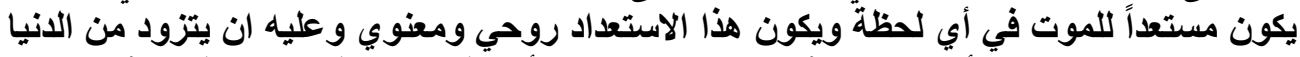

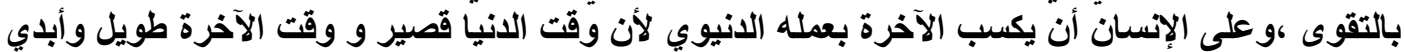

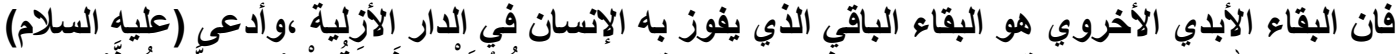

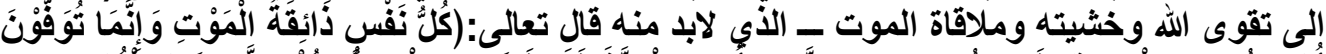

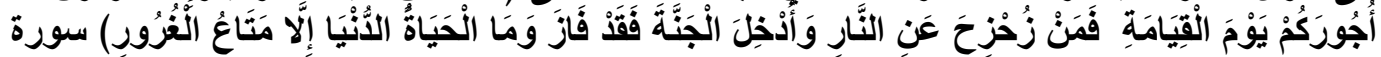

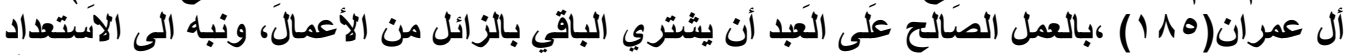

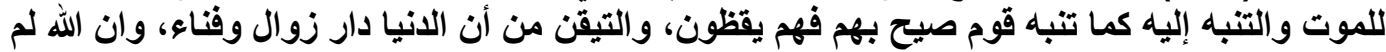

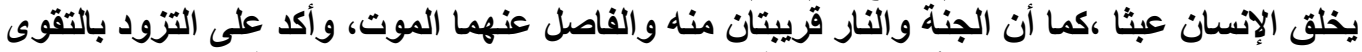

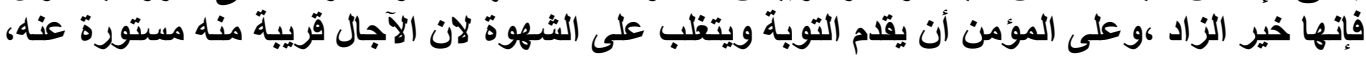

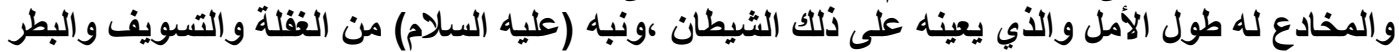

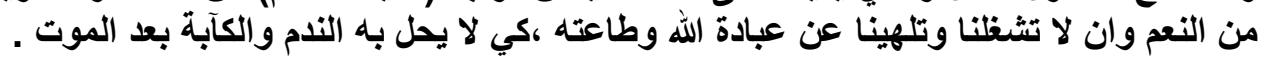

نستتتج من الخطبة السابقة الجوانب التربوية الآتية :

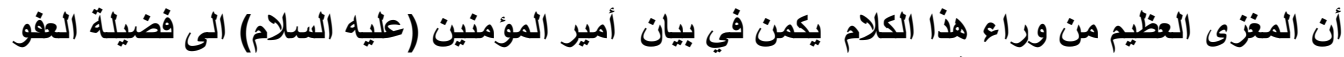

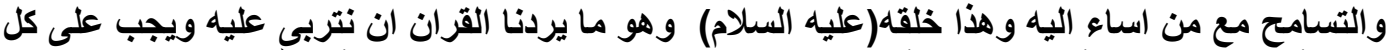

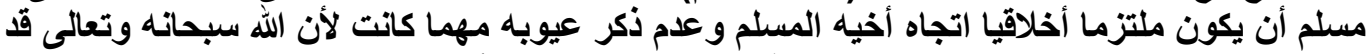

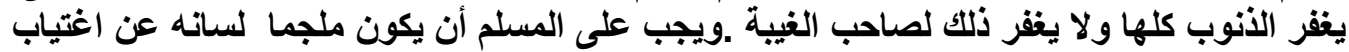

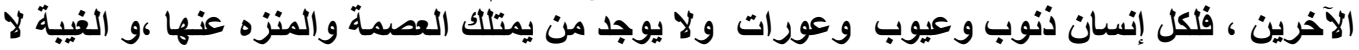

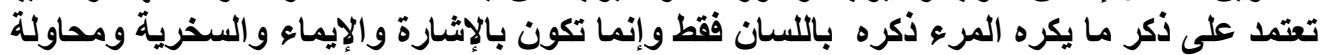

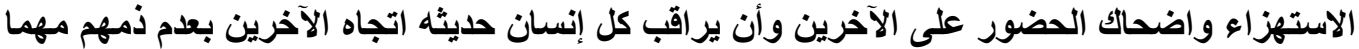




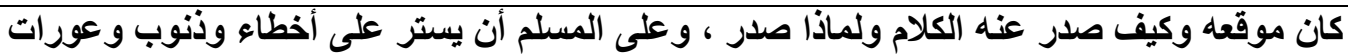

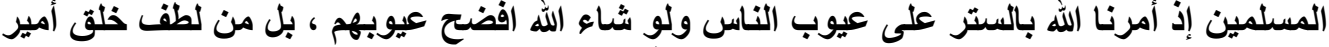

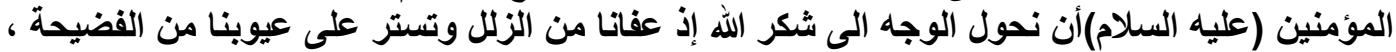

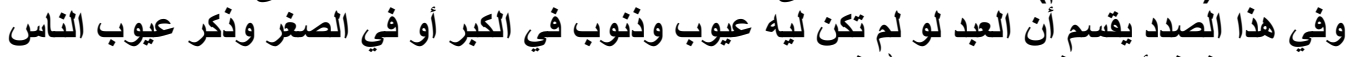

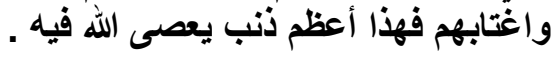
المبحث الخامس أولا :الاستنتاجات

اـ للإمام منزلة علمية واجتماعية وفكرية في قلوب المسلمين جميعاً . r- استخدم الإمام علي (عليه السلام ) كثيرا من الأساليب التربوية في الحياة الاجتماعي. بـ يرى امير المؤمنين علي (عليه السلام) أن التربية والتعليم من أكثر المهن التي تحتاج الى تعلم . ع - يؤكد الإمام علي (عليه السلام )على الإنسان أن يعمل بكل ما يرضي الله لأن الموت طالبه. ثانياً :التوصيات :

ا ـ العمل على تأصيل الدراسات التربوية من خلال دراسة أفكار السلف الصالح للاستفادة منها. و ـ الاهتمام بشكل خاص بلراسة خطب الإمام علي (عليه السلام) للخروج بالمزيد من الفوائد التريوية والاجتماعية . - و الاتمام. rـ الاهتمام بأفكار وتوجيهات أعلام التربية الإسلامية والعمل على توظيفها تربويـاً . : المثاً : المقترحات : اـ حث الطلبة على عمل بحوث التخرج في الفكر التربوي الإسلامي . r ـ العمل على دراسات في كتاب نهج البلاغة وخصوصاً للعاملين في حقل التربية والتعليم . بـ إجراء دراسة مقارنة في الفكر التربوي للإمام علي(عليه السلام ) مع الفكر التربوي لعلماء الأمة في

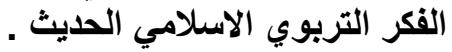


9-الطبري،محب الدين أحمد، ذخائر العقبى في مناقب ذوي القربى ،بيروت- لبنان ، دار المعرفة (د -

^-شبلي، أحمد ، تاريخ التربية الإسلامية ، القاهرة ، مكتبة الأنجلو المصرية ، 9 ام.

V-السعيدي ، أم زهراء ، التربية من منظور إسلامي ، طا، لبنان ، مؤسسة الكوثر النسائية ا 1 ـ ب م.

צ-الرشدان،عبد الله زاهي ،الفكر التريوي الإسلامي، طا، الأردن - عمان ، دار وائل للطباعة والنشر

$$
\cdot \hat{P} \cdot \boldsymbol{s}
$$

ه-الخطيب، عبد الكريم ، أسس علم الاجتماع التريوي ، جr ، طرابلس ، جامعة الفاتح ه9 ب أهـ. ع -الخطيب، طه ياسين ناصر، القيم التريوية في موعظة لقمان لابنه، مجلة العلوم التريوية والنفسية، جامعة بغداد، البحرين، كلية الآداب، ب . . بام .

ب- البركاتي ، نواف بن نامي بن عبد الله ، بعض الآراء المستتبطة من خطب وأقوال الخليفة الراشد علي بن أبي طالب (عليه السلام ) ، أطروحة ماجستير تقدم بها الى مجلس كلية التربية بمكة المكرمة ، جامعة

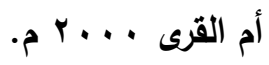

r - دخيل ، علي محمدعلي ، شرح نهج البلاغة ، طا ، العتبة الكاظمية المقدسة،بغداد ب ا • م.

ا -الأديب ،علي محمد محسن ، منهج التربية عند الإمام علي (عليه السلام)،النجف الثرف،المطبعة

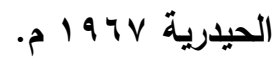

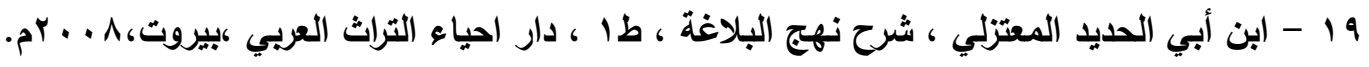


1 ا - هيفا، راجي أنور ، الإمام علي (عليه السلام)،في الفكر المسيحي المعاصر،طا ،دار العلوم للطباعة

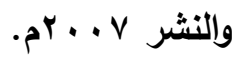

V - رضا، محمد جواد، حدود القدرة والاحباط في التخطيط التربوي في العالم العربي ،مجلة العلوم

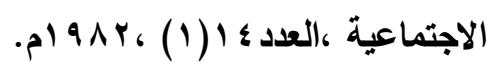

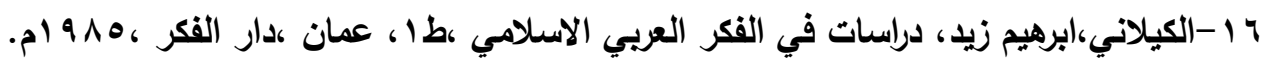
ه ا-التحلاوي، عبد الرحمن، اصول التربية الاسلامية واساليبها، دمشق، ؛ 99 ام.

ع ا-المسعودي،أبي الحسن علي بن الحسين بن علي ،مروج الأب ومعادن الجوهر، جr، مؤسسة

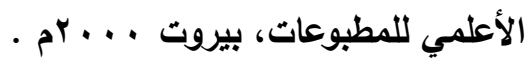

ب ا -المرزوقي، آمال بنت حمزةمضامين تريوية في سورة البقرة. دراسات تريوية ،القاهرة، عامل الكتب، . 1990 r ا-الكاندهلوي ، محمد يوسف ، حياة الصحابة ، دار المعرفة، ، بيروت ب99 ام. 9 ام. 1 ا-فهد،ابتسام محمد ، الفكر التريوي العربي الإسلامي لبعض فلاسفة العرب المسلمين بين القرنين الرابع والسادس الهجري، أطروحة دكتوراه غير منشورة ، كلية التربية ، ابن رشد ، جامعة بغداد ع 9 ام. • ا-طهطاوي، سيد احمد، القيم التريوية في القصص القراني،طا ، دار الفكر العربي، مصر ،999 ام. 